\title{
Effects of Glycerol and Shikimic Acid on Rapamycin Production in Streptomyces rapamycinicus
}

\author{
Huyen Thi Huong La, Thao Kim Nu Nguyen, Hang Thuy Dinh, Quyen Minh Huynh Nguyen, and Minh Hong Nguyen* \\ VNU Institute of Microbiology and Biotechnology, Vietnam National University, Hanoi. E2 buliding, 144 Xuan Thuy Street, Cau Giay District, \\ Hanoi, Vietnam
}

Received: January 3, 2020 / Revised: February 22, 2020 / Accepted: March 5, 2020

\begin{abstract}
Rapamycin, derived from Streptomyces rapamycinicus, is an important bioactive compound having a therapeutic value in managing Parkinson's disease, rheumatoid arthritis, cancer, and AIDS. Because of its pharmaceutical activity, studies over the past decade have focused on the biosynthesis of rapamycin to enhance its yield. In this study, the effect of $\operatorname{rap} G$ on rapamycin production was investigated. The rapG expression vector was constructed by utilizing the integration vector pSET152 under the control of the erythromycin resistance gene $\left(\mathrm{erm}^{*}\right)$, a strong constitutive promoter. The rapamycin yield of wild type (WT) and WT/ rapG overexpression mutant strains, under fermentation conditions, was analyzed by high-performance liquid chromatography (HPLC). Our results revealed that overexpression of rapG increased rapamycin production by approximately 4.9 -fold $(211.4 \mathrm{mg} / \mathrm{l})$ in MD1 containing $15 \mathrm{~g} / \mathrm{l}$ of glycerol, compared to that of the WT strain. It was also found that Illicium verum powder $(10 \mathrm{~g} / \mathrm{l})$, containing shikimic acid, enhanced rapamycin production in both WT and WT/rapG strains. Moreover, the amount of rapamycin produced by the WT/rapG strain was statistically higher than that produced by the WT strain. In conclusion, the addition $15 \mathrm{~g} / \mathrm{l}$ glycerol and $15 \mathrm{~g} / \mathrm{I}$. verum powder produced the optimal conditions for rapamycin production by WT and $\mathrm{WT} /$ rapG strains.
\end{abstract}

Keywords: Rapamycin, WT/rapG, Illicium verum extract, Streptomyces rapamycinicus

\section{Introduction}

Rapamycin is an important bioactive compound derived from Streptomyces rapamycinicus, which was first isolated from a soil sample in 1975 [1]. Rapamycin is a macrolide antibiotic with antifungal and immunosuppressive properties [2]. Also, recent reports indicated that rapamycin has therapeutic value in managing Parkinson's disease [3], rheumatoid arthritis [4], cancer [5], and AIDS [6]. Based on a sequence analysis and genetic engineering study, the function of rapamycin's synthetic rap $G$ gene was identified as an important positive regulatory gene in rapamycin biosynthesis. The sequence

\section{*Corresponding author}

Tel: +84-24-3754-7407, Fax: +84-24-3754-7407

E-mail: nguyenminh-imbt@vnu.edu.vn

(c) 2020, The Korean Society for Microbiology and Biotechnology analysis showed that $\operatorname{rap} G$ is similar to other positive regulatory proteins, such as the SoxS and Rob proteins of Escherichia coli [7]. The rapG overexpression under ActII-ORF4/ $\mathrm{P}_{\text {actI }}$ promoter in $S$. rapamycinicus significantly enhanced rapamycin production under specific fermentation conditions [8].

Glycerol is not only abundant and inexpensive, but can also facilitate maximum yield of antibiotics; therefore, the optimization of glycerol-based media seems to be an economical means of rapamycin production [9, 10]. Rapamycin can be classified as a cyclohexane carboxylic acid antibiotic. The biosynthesis of rapamycin begins with a unique cyclohexane unit derived from the shikimic acid pathway [11]. It has previously been reported that shikimic acid enhances rapamycin production; however, it is strain-dependent [10].

Most efforts have focused on the optimization of physi- 
ological factors for better rapamycin production from wild type strains of Streptomyces sp. [9, 12-15]. A few articles have reported that the optimal fermentation process for the production of rapamycin from mutant strains can be obtained by UV mutagenesis [10]. In this study, the effects of glycerol and shikimic acid on the rapamycin biosynthesis of $S$. rapamycinicus wild type and $\operatorname{rap} G$ overexpression mutant strains, in several rapamycin fermentation media, were investigated. Moreover, Illicium verum powder, used for obtaining shikimic acid, was optimized for industrial-scale production of rapamycin.

\section{Materials and Methods}

\section{Bacterial strains}

All strains and plasmids that were used in this study were described in Table 1. Streptomyces rapamycinicus DSM 41530 (WT strain) was used in the study. The WT and its recombinant strains were cultured at $28^{\circ} \mathrm{C}$ on yeast extract-starch soluble (YS) agar plates. E. coli DH5 $\alpha$ was used for the propagation of plasmids using a standard protocol [16]. The pGEM T-Easy vector system (Promega, US) was used for the subcloning process. $E$. coli ET12567, consisting of plasmid pUZ8002, was used to conjugate and transfer the target plasmid to S. rapamycinicus spores [17]. S. rapamycinicus mutant strain was cultured in media containing $50 \mu \mathrm{g} / \mathrm{ml}$ apramycin. E. coli ET12567/pUZ8002 strains were cultured in Lysogeny Broth (LB) containing $50 \mu \mathrm{g} / \mathrm{ml}$ rapramycin, $50 \mathrm{\mu g} / \mathrm{ml}$ chloramphenicol, and $50 \mathrm{\mu g} / \mathrm{ml}$ kanamycin.
Table S1. Primers used in this study.

\begin{tabular}{|c|c|}
\hline Primer & Sequence \\
\hline \multicolumn{2}{|c|}{ For Mutagenesis } \\
\hline rapGF & GGTCTAGAACCAACGGCGCTGGAGCGGAG \\
\hline $\operatorname{rapGR}$ & GGTCTAGAGGTCAGCTGTCGGTCAGCCCGGTTG \\
\hline \multicolumn{2}{|c|}{ For real-time PCR } \\
\hline rrsA1090F & GGTCAACTCGGAGGAAGGTG \\
\hline rrsA1306R & ACGTATTCACCGCAGCAATG \\
\hline rapG84F & AGGATTCTTCCAGGCCTTCC \\
\hline rapG293R & TACATCCGTACCCGGTCCTC \\
\hline
\end{tabular}

\section{Construction of rapG overexpression mutant strain}

The rapG overexpression mutant strain was constructed by using the method described by Kuscer with some modifications [8]. Briefly, the rapG gene was amplified from the genomic DNA of $S$. rapamycinicus DSM 41530 by means of polymerase chain reaction (PCR) method using the primers (Table S1). The PCR products of $\operatorname{rap} G$ were purified and cloned into a pGEM T-Easy vector to produce pGEM-rapG. The sequence-verified fragments, which were obtained by digesting pGEM$\operatorname{rap} G$ with $\mathrm{XbaI}$ enzyme, were then joined with pSET152 to produce $\mathrm{pRapG}$, which was then sequenced. Thereafter, pRapG was introduced into $S$. rapamycinicus by conjugation using E. coli ET12567/pUZ8002, as described by Kurniawan [17], to yield the WT/rapG overexpression mutant strain. The genotypes of WT and WT/rapG overexpression mutant strain were verified using Southern blot hybridization. For southern blot hybridization, rapG was used as a probe and the genomic DNAs were digested

Table 1. Bacterial strains and plasmids used in this study.

\begin{tabular}{|c|c|c|}
\hline Strain/plasmid & Characteristics & Reference/Source \\
\hline \multicolumn{3}{|l|}{ Bacterial strains } \\
\hline Escherichia coli DHa & $\mathrm{F}-\mathrm{rec} A \mathrm{lac} Z \Delta \mathrm{M} 15$ & [16] \\
\hline Escherichia coli ET12567/pUZ8002 & $\begin{array}{l}\text { Non-methylating ET12567 containing non-transmissible RP4 deriva- } \\
\text { tive plasmid } \\
\text { pUZ8002, Cmlr, Tetr, Kanr }\end{array}$ & {$[17]$} \\
\hline Streptomyces rapamycinicus DSM 41530 & Wild-type strain & [1] \\
\hline WT/rapG & Wild-type with integrative plasmid pRapG04, Apar ${ }^{r}$ & This study \\
\hline \multicolumn{3}{|l|}{ Plasmids } \\
\hline pGEM T-Easy & & Promega \\
\hline pSET152 (ermEp*) & Integrative plasmid containing ermE $p^{*}$, oriT, attP, $\Phi C 31$ int and aac(3)IV & [23] \\
\hline pRapG & $\begin{array}{l}\text { pSET152 (ermEp*)-based integrative plasmid containing a single copy } \\
\text { of rapG, Apar }\end{array}$ & This study \\
\hline
\end{tabular}


by BamHI and KpnI.

\section{Analysis of gene expression}

For the study of gene expression, cells harvested at $48 \mathrm{~h}$ were subjected to total RNA extraction by using TRIzol ${ }^{\mathrm{TM}}$ reagent (ThermoFisher Scientific, USA). Genomic DNA was digested with RNase-free DNase I (ThermoFisher Scientific) and RNA concentration was measured by using the NanoDrop 2000 Spectrophotometer (Thermo). Reverse transcription to cDNA was conducted with a Maxima First Strand cDNA Synthesis Kit for RT-qPCR (ThermoFisher Scientific). The rrsA (16s rRNA) gene was employed as a reference for the real-time PCR assay [18]. Specific primers were listed in Table S1. Real-time PCR was performed with a Mastercycler ${ }^{\circledR}$ RealPlex $^{2}$ (Eppendorf, USA) by using GoTaq ${ }^{\circledR}$ qPCR Master Mix (Promega, USA) under the following conditions: 2 min at $95^{\circ} \mathrm{C}, 40$ cycles of $15 \mathrm{~s}$ at $95^{\circ} \mathrm{C}$, and final extension for $1 \mathrm{~min}$ at $60^{\circ} \mathrm{C}$. For each cDNA sample, a cycle threshold value $\left(C_{\mathrm{t}}\right)$ of the reference gene was subtracted from that of the target gene to obtain $\Delta C_{\mathrm{t}}$, and the expression of each gene was quantified by $2^{-\Delta C \mathrm{t}}$.

\section{Analysis of rapamycin production}

The WT and WT/rapG overexpression mutant strains were cultivated in YS medium. At first, seed cultures were cultivated at $28^{\circ} \mathrm{C}$ on an YS agar plate for $96 \mathrm{~h}$, thereafter 10 cubes of agar containing the mycelia were transferred to $75 \mathrm{ml}$ of fresh medium and shaken at 200 rpm for $72 \mathrm{~h}$ at $28^{\circ} \mathrm{C}$. The media used for rapamycin production were as follows: MD1 containing $40 \mathrm{~g} / \mathrm{l}$ dextrin, $30 \mathrm{~g} / \mathrm{l}$ soybean meal, $5 \mathrm{~g} / \mathrm{l} \mathrm{NaCl}, 3 \mathrm{~g} / \mathrm{N} \mathrm{Na}_{2} \mathrm{HPO}_{4}$, and $2 \mathrm{~g} / \mathrm{l}$ L-Lysine $\mathrm{HCl}$ and had a $\mathrm{pH}$ of 5.0 [10]; $\mathrm{MD} 2$ containing $20 \mathrm{~g} / \mathrm{l}$ glucose, $5 \mathrm{~g} / \mathrm{l} \mathrm{KH}_{2} \mathrm{PO}_{4}$, and $20 \mathrm{~g} / \mathrm{l}$ soybean meal and had a pH of 6.0 [19]; MD3 containing $6 \mathrm{~g} / \mathrm{l}$ glucose 6 , $10 \mathrm{~g} / \mathrm{l}$ soybean meal, $0.025 \mathrm{~g} / \mathrm{K}_{2} \mathrm{HPO}_{4}, 8 \mathrm{~g} / \mathrm{l}$ sorbitol, and $0.2 \mathrm{~g} / \mathrm{l}\left(\mathrm{NH}_{4}\right)_{2} \mathrm{SO}_{4}$ and had a pH of 6,5 [20]; and MD4 containing $22 \mathrm{~g} / \mathrm{l}$ glucose, $10 \mathrm{~g} / \mathrm{l}$ malt extract, $0.3 \mathrm{~g} / \mathrm{l}$ casein, $5.3 \mathrm{~g} / \mathrm{l}\left(\mathrm{NH}_{4}\right)_{2} \mathrm{SO}_{4}, 5 \mathrm{~g} / \mathrm{l} \mathrm{NaCl}, 0.3 \mathrm{~g} / \mathrm{l} \mathrm{Na} 2 \mathrm{SO}_{4}, 4 \mathrm{~g} / \mathrm{l}$ $\mathrm{KH}_{2} \mathrm{PO}_{4}, \quad 3 \mathrm{~g} / \mathrm{l} \quad \mathrm{CaCO}_{3}, \quad 0.06 \mathrm{~g} / \mathrm{l} \quad \mathrm{ZnSO}_{4} \cdot 7 \mathrm{H}_{2} \mathrm{O}, \quad 0.06 \mathrm{~g} / \mathrm{l}$ $\mathrm{MgSO}_{4} \cdot 7 \mathrm{H}_{2} \mathrm{O}, \quad 0.1 \mathrm{~g} / \mathrm{l} \quad \mathrm{FeSO}_{4} \cdot 7 \mathrm{H}_{2} \mathrm{O}$, and $0.012 \mathrm{~g} / \mathrm{l}$ $\mathrm{MnSO}_{4} \cdot \mathrm{H}_{2} \mathrm{O}$ and had a pH of 7.2 [21]. Either glycerol or I. verum extract was then added into the fermentation media. To obtain the extract, I. verum powder was placed in a teabag, dipped into $50 \mathrm{ml}$ reverse osmosis (RO) water and autoclaved at $121^{\circ} \mathrm{C}$. In order to analyse
Table 2. Mobile phase of the HPLC analysis.

\begin{tabular}{ccc}
\hline Time $(\min )$ & $\mathrm{H}_{2} \mathrm{O}(\%)$ & Acetonitrile (\%) \\
\hline 0.00 & 85 & 15 \\
3.00 & 85 & 15 \\
25.00 & 15 & 85 \\
29.00 & 15 & 85 \\
32.00 & 85 & 15 \\
35.00 & 85 & 15 \\
\hline
\end{tabular}

the rapamycin, the culture broth was separated from the mycelia. The mycelia were mixed with $7.5 \mathrm{ml}$ methanol and then shaken intensively for $4 \mathrm{~h}$ at $30^{\circ} \mathrm{C}$. After centrifugation at $4000 \times g$ for $20 \mathrm{~min}$, the suspension was transferred to a culture broth, which was extracted with an equal volume of ethyl acetate, and then filtered. A fraction of this solution was then subjected to HPLC analysis. An Agilent 1260 series HPLC system equipped with an Eclipse XDB- C18 $(4,6 \times 150 \mathrm{~mm}, 5 \mu \mathrm{m})$ reversed phase analytical column was used. The mobile phase consisted of a mixture of acetonitrile and water (Table 2) and the eluate was monitored at $280 \mathrm{~nm}$. At least three separate cultivations and extractions were carried out to obtain an average production yield of rapamycin.

\section{Results and Discussion}

\section{Overexpression of rapG gene in S. rapamycinicus}

To investigate the functions of $\operatorname{rap} G$ gene in the regulation of rapamycin production in $S$. rapamycinicus, the gene was introduced and overexpressed in the S. rapamycinicus wild-type strain. The vector for overexpression of rapG was constructed by employing the integration vector pSET152 as described in Materials and Methods. The $\varphi$ C31-based integrating plasmid pRapG, under the control of a strong constitutive $\mathrm{ermE}^{*}$ promoter, was introduced into the wild-type $S$. rapamycinicus strain at the bacteriophage $\varphi \mathrm{C} 31$ attachment site $(a t t B)$ generating WT/rapG. The pRapG plasmid can be maintained in the chromosome of overexpression mutant strains at integrated sites. A fragment of $993 \mathrm{bp}$ of the rap $G$ gene, obtained by PCR, was digested by XbaI, after which it was added to pSET152 to generate the pRapG plasmid (Fig. 1A). The overexpression mutant was confirmed by Southern blot hybridization (Fig. 1B). A hybridizing 
A

$\underset{r a p G}{\stackrel{\text { pSET152 }}{\text { XbaI }} \text { M }} \stackrel{\text { PRapG }}{\text { XbaI }}$

B
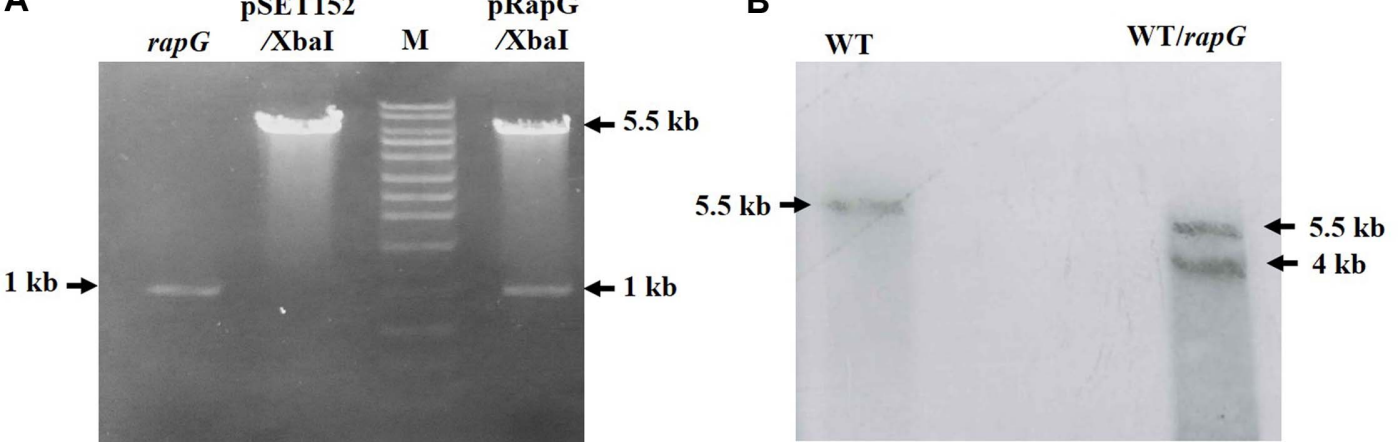

Fig. 1. (A) Gel electrophoresis of the PCR of the rapG gene, PSET152 digested by Xbal, Marker 100 bp DNA ladder and pRapG digested by Xbal, respectively. (B) Southern blot analysis of mutants with one or two rapG genes deleted. The DNA from the WT strain and WT/rapG strain were digested by BamHI and Kpnl and hybridized with the probe covering the rapG region.

band of approximately $4.0 \mathrm{~kb}$ was found for the WT strain whereas in the $\operatorname{rap} G$ overexpression mutant, 2 hybridizing bands of approximately 4.0 and $5.5 \mathrm{~kb}$ were observed, indicating that $\mathrm{pRapG}$ was introduced at a site different from that of the WT genome.

\section{Enhanced production of rapamycin with glycerol and Illicium verum powder extract}

To evaluate the effect of overexpression of $\operatorname{rap} G$ on rapamycin yield, fermentations using several media were performed and the yield of rapamycin monitored to evaluate the fermentation process. The fermentation media MD1, MD2, MD3 and MD4 were selected from previous studies. Both the WT and rapG overexpression mutant strains produced the highest quantity of rapa- mycin in the MD1 medium, compared to the other media. The yield of rapamycin of the WT and rap $G$ overexpression mutant strains were $39.0 \pm 4.0$ and $54.5 \pm 15.0$ $\mathrm{mg} / \mathrm{l}$, respectively (Fig. 2A). However, there was no significant difference between the rapamycin yield of the WT and $\mathrm{WT} / \mathrm{rap} G$ strains cultured in the MD1 medium.

Glycerol is an economical feedstock for fermentation processes, and it is reported to increase the yield of rapamycin biosynthesis. The addition of $36.2 \mathrm{~g} / \mathrm{l}$ of glycerol yielded the maximum rapamycin production of Streptomyces hygroscopicus wild-type strain [9]. In this study, the effect of glycerol on rapamycin production was tested using several fermentation media and the data were shown in Fig. 2B. Our results confirmed that glycerol facilitated rapamycin production of the WT strain. For
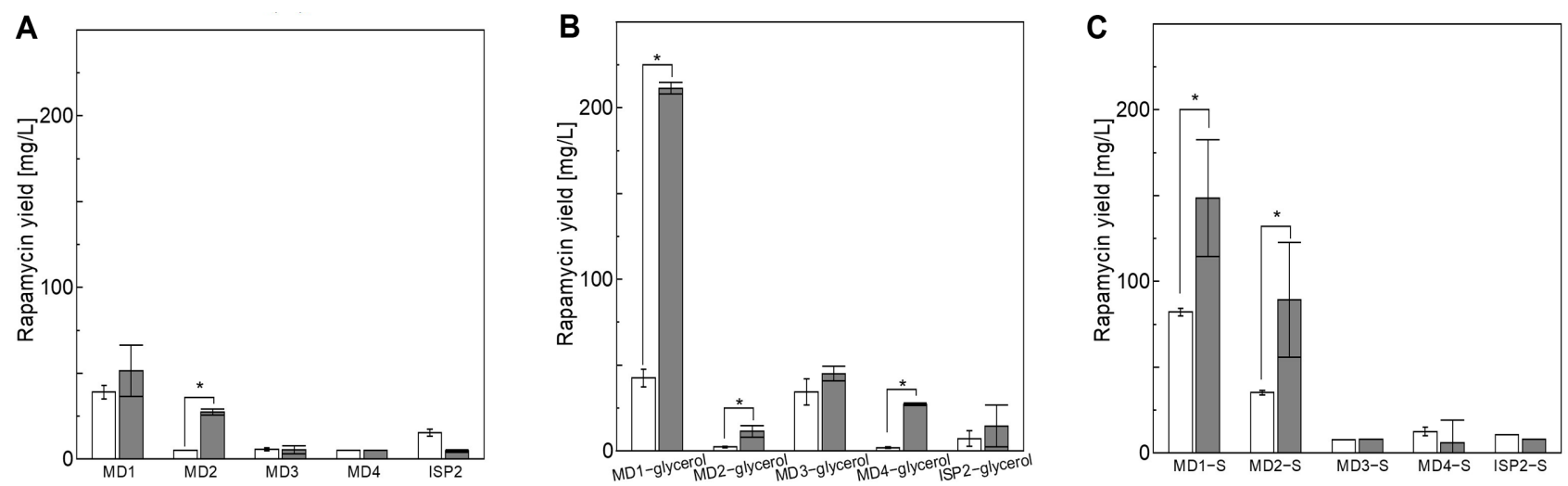

Fig. 2. Variability of rapamycin yields from S. rapamycinicus WT (open column) and WT/rapG (closed column) cultured in fermentation media (A), media containing $15 \mathrm{~g} / \mathrm{l}$ glycerol (B) and media containing $10 \mathrm{~g} / \mathrm{l}$ Illicium verum powder. The data are the means of measurements obtained from at least three independent experiments. The statistical significance among the data sets was assessed by Student's t-test $\left({ }^{*} p<0.05\right)$. 
example, the rapamycin production of the WT strain in the MD1-glycerol medium was slightly higher than that in the original MD1 medium. Moreover, the rapamycin production of the WT strain in the MD3-glycerol medium was significantly higher than that in the original MD3 medium. For rapamycin production of the $\operatorname{rap} G$ overexpression mutant strain, the addition of $15 \mathrm{~g} / \mathrm{l}$ glycerol significantly enhanced the production of rapamycin in MD1, MD2 and MD4 media compared to those media without added glycerol. For example, the yield of rapamycin in MD1-glycerol of the WT/rapG strain was 4.1 fold higher than that in the original MD1 medium. Interestingly, overexpression of $\operatorname{rap} G$ increased rapamycin production by approximately 4.9 fold to $211.4 \mathrm{mg} / \mathrm{l}$ in MD1 containing $15 \mathrm{~g} / \mathrm{l}$ glycerol compared to that of the WT strain. Thus, the MD1-glycerol is chosen to use in further experiments.

The elucidation of rapamycin biosynthesis indicates that intracellular supplies of shikimic acid [10-12] are vital to the construction of the rapamycin scaffold. However, shikimic acid is an expensive material that cannot be adopted in large-scale fermentation. It was reported that shikimic acid could easily be extracted from $I$. verum powder using hot water at $120^{\circ} \mathrm{C}$ [22]. Thus, it was hypothesized that the addition of I. verum extraction liquid positively affects rapamycin production. The results showed that both the WT and rapG overexpression mutant strains produced plentiful rapamycin in the MD1 and MD2 media which contained $10 \mathrm{~g} / \mathrm{l}$ of $\mathrm{I}$. verum extraction (Fig. 2C). Moreover, the amount of rapamycin produced by the $\mathrm{WT} /$ rap $G$ strain was statistically higher than that produced by the WT strain, especially in the MD1-shikimic acid medium.

In order to understand the effect of both glycerol and shikimic acid on rapamycin production, extraction liquid of 5,10 , and $15 \mathrm{~g} / \mathrm{I}$. verum was added to the MD1-glycerol media. For the WT strain, $130.5 \pm 5.1,120.0 \pm 15.1$, and $149.0 \pm 24.1 \mathrm{mg} / \mathrm{l}$ rapamycin was produced in media containing 5,10 , and $15 \mathrm{~g} / 1 \mathrm{I}$. verum powder, respectively (Fig. 3). Our result revealed that the combination of glycerol and shikimic acid, found in I. verum extraction liquid, increased the rapamycin production of WT strain by approximately 3 fold, compared to that in the original medium. We observed an increase in the rapamycin production of WT/rap $G$ of by 1.3 to 1.4-fold compared to the WT strain. Besides, the addition of $15 \mathrm{~g} / \mathrm{l}$ glycerol and

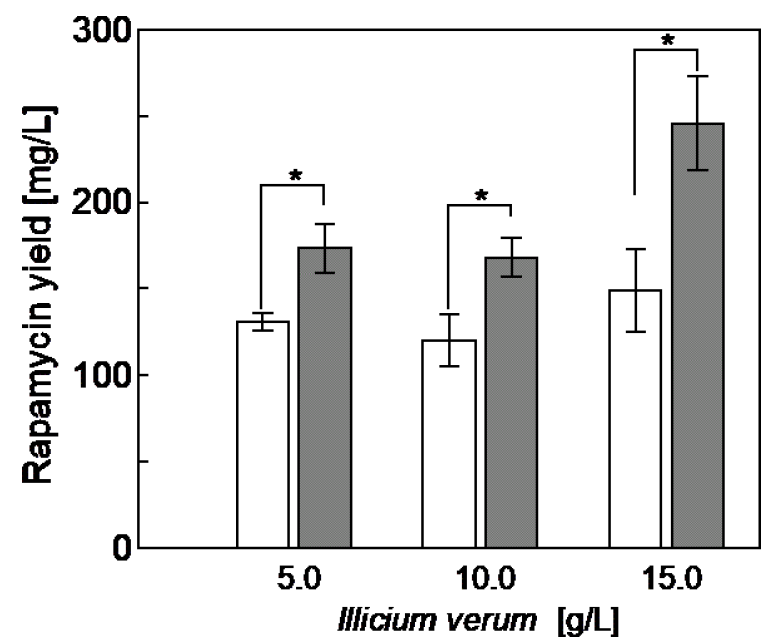

Fig. 3. Variability of rapamycin yields from S. rapamycinicus WT (open column) and WT/rapG (closed column) cultured with MD1 containing $15 \mathrm{~g} / \mathrm{l}$ glycerol and Illicium verum powder. The data are the means of measurements obtained from at least three independent experiments. The statistical significance among the data sets was assessed by Student's t-test $\left({ }^{*} p<0.05\right)$.

$15 \mathrm{~g} / \mathrm{I}$ I. verum powder enhanced the rapamycin production of $\mathrm{WT} / \mathrm{rap} G$ compared to those in MD1-glycerol and MD1-shikimic acid.

In a previous study, under flask cultivation conditions, $76.2 \pm 4.7 \mathrm{mg} / \mathrm{l}$ of rapamycin was obtained from the WT strain in an optimized glycerol-based medium [9]. In our study, WT strain produced $149.0 \pm 24.1 \mathrm{mg} / \mathrm{l}$ in MD1glycerol containing $15 \mathrm{~g} / \mathrm{l}$ I. verum powder. Moreover, the real-time PCR showed that $\operatorname{rap} G$ expression in WT/ $\operatorname{rap} G$ was significantly higher than WT in MD1-glycerol medium (Fig. 4). As the result, the overexpression of rap $G$, under the control of the ermE* promoter, significantly enhanced the biosynthesis of rapamycin compared to the WT strain in the MD1-glycerol medium. Also, the overexpression of rapG in $\mathrm{WT} / \mathrm{rap} G$ strain resulted in the higher rapamycin yield of the WT/rapG strain in MD1-shikimic acid (Fig. 4). In the medium containing $15 \mathrm{~g} / \mathrm{l}$ glycerol and $15 \mathrm{~g} / \mathrm{l}$ I. verum powder, the rapG expression in WT/ rapG strain was 6.1-fold higher than in WT strain. Thus, it was suggested that the MD1glycerol, MD1-shikimic acid and MD1-glycerol and shikimic acid media, combined with rapG overexpression, increased rapamycin production by 4.4, 4.3 and 6.3 fold, respectively, compared to that of the WT strain in the MD1 original medium. Therefore, it is evident that rapG plays a role in rapamycin biosynthesis of both the glyc- 


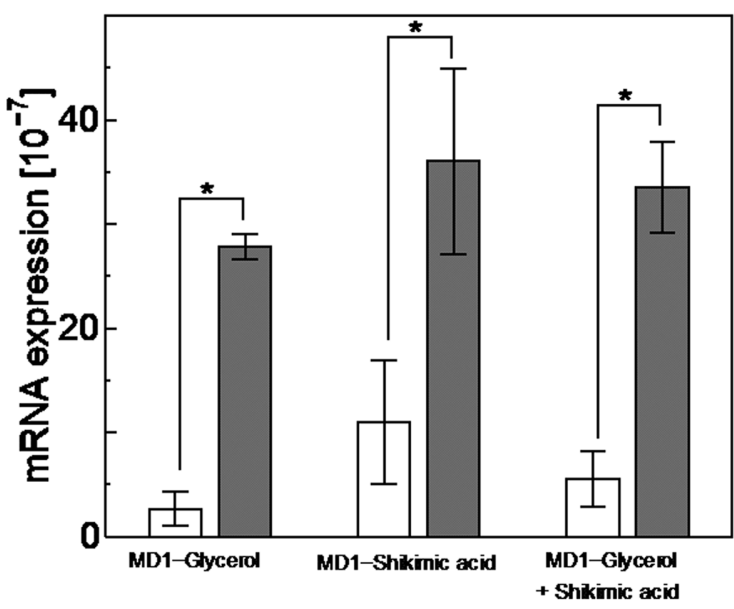

Fig. 4. Expressions of rapG in respective cells of WT and WT/ rapG strains at $48 \mathrm{~h}$ in MD1-glycerol, MD1-shikimic and MD1glycerol with $15 \mathrm{~g} / \mathrm{l}$ Illicium verum powder media. The data are the means of measurements obtained from three independent experiments. The statistical significance among the data sets was assessed by the Student's t-test $\left({ }^{*} p<0.05\right)$.

erol and the shikimic acid pathway. The I. verum powder is abundant and economic, therefore, it is believed that I. verum powder could be used for obtaining shikimic acid for industrial-scale production of rapamycin.

In conclusion, $\operatorname{rap} G$ overexpression facilitated rapamycin biosynthesis in presence of the glycerol and the shikimic acid. This research provided information on the systematic optimization of rapamycin production from the WT and WT/rapG overexpression mutant strain. The addition $15 \mathrm{~g} / \mathrm{l}$ glycerol and $15 \mathrm{~g} / \mathrm{I}$ I. verum powder was the optimal condition for rapamycin production of $\mathrm{WT}$ and $\mathrm{WT} /$ rap $G$ strains.

\section{Acknowledgments}

This work was supported by project QG.17.47 from Vietnam National University, Hanoi. We would like to thank Editage (www.editage.com) for English language editing. We would like to thank Ms. Iris Bertani from ICGEB for technical assistance in Southern blot hybridization experiment.

\section{Conflict of Interest}

The authors have no financial conflicts of interest to declare.

\section{References}

1. Vezina C, Kudelski A, Sehgal SN. 1975. Rapamycin (AY-22,989), a new antifungal antibiotic. I. Taxonomy of the producing streptomycete and isolation of the active principle. J. Antibiot. 28: 721726.

2. Park SR, Yoo YJ, Ban YH, Yoon YJ. 2010. Biosynthesis of rapamycin and its regulation: past achievements and recent progress. $J$. Antibiot. 63: 434-441.

3. Tain LS, Mortiboys H, Tao RN, Ziviani E, Bandmann O, Whitworth AJ. 2009. Rapamycin activation of 4E-BP prevents parkinsonian dopaminergic neuron loss. Nat. Neurosci. 12: 1129-1135.

4. Shao P, Ma L, Ren Y, Liu H. 2017. Modulation of the immune response in rheumatoid arthritis with strategically released rapamycin. Mol. Med. Rep. 16: 5257-5262.

5. Zou CY, Smith KD, Zhu QS, Liu J, McCutcheon IE, Slopis JM, et al. 2009. Dual targeting of AKT and mammalian target of rapamycin: a potential therapeutic approach for malignant peripheral nerve sheath tumor. Mol. Cancer Ther. 8: 1157-1168.

6. Nicoletti F, Lapenta C, Donati S, Spada M, Ranazzi A, Cacopardo B, et al. 2009. Inhibition of human immunodeficiency virus (HIV-1) infection in human peripheral blood leucocytes-SCID reconstituted mice by rapamycin. Clin. Exp. Immunol. 155: 28-34.

7. Molnar I, Aparicio JF, Haydock SF, Khaw LE, Schwecke T, Konig A, et al. 1996. Organisation of the biosynthetic gene cluster for rapamycin in Streptomyces hygroscopicus: analysis of genes flanking the polyketide synthase. Gene. 169: 1-7.

8. Kuscer E, Coates N, Challis I, Gregory M, Wilkinson B, Sheridan R, et al. 2007. Roles of rapH and rapG in positive regulation of rapamycin biosynthesis in Streptomyces hygroscopicus. J. Bacteriol. 189: 4756-4763.

9. Kim YH, Park BS, Bhatia SK, Seo HM, Jeon JM, Kim HJ, et al. 2014. Production of rapamycin in Streptomyces hygroscopicus from glycerol-based media optimized by systemic methodology. J. Microbiol. Biotechnol. 24: 1319-1326.

10. Zhu X, Zhang W, Chen X, Wu H, Duan Y, Xu Z. 2010. Generation of high rapamycin producing strain via rational metabolic pathwaybased mutagenesis and further titer improvement with fedbatch bioprocess optimization. Biotechnol. Bioeng. 107: 506-515.

11. Paiva NL, Roberts MF, Demain AL. 1993. The cyclohexane moiety of rapamycin is derived from shikimic acid in Streptomyces hygroscopicus. J. Ind. Microbiol. Biotechnol. 12: 423-428.

12. Fang A, Demain AL. 1995. Exogenous shikimic acid stimulates rapamycin biosynthesis in Streptomyces hygroscopicus. Folia Microbiol. (Praha) 40: 607-610.

13. Lee MS, Kojima I, Demain AL. 1997. Effect of nitrogen source on biosynthesis of rapamycin by Streptomyces hygroscopicus. J. Ind. Microbiol. Biotechnol. 19: 83-86.

14. Yen HW, Hsiao HP. 2013. Effects of dissolved oxygen level on rapamycin production by pellet-form of Streptomyces hygroscopicus. J. Biosci. Bioeng. 116: 366-370.

15. Yen H-W, Hsiao H-P, Chen L-J. 2013. The enhancement of rapamycin production using Streptomyces hygroscopicus through a simple $\mathrm{pH}$ shifted control. J. Taiwan Inst. Chem. E. 44: 743-747.

16. Hanahan D. 1983. Studies on transformation of Escherichia coli with plasmids. J. Mol. Biol. 166: 557-580. 
17. Kurniawan $\mathrm{YN}$, Kitani S, lida A, Maeda A, Lycklama a Nijeholt J, Lee YJ, et al. 2016. Regulation of production of the blue pigment indigoidine by the pseudo gamma-butyrolactone receptor FarR2 in Streptomyces lavendulae FRI-5. J. Biosci. Bioeng. 121: 372-379.

18. Dai D, Pu T, Liang J, Wang Z, Tang A. 2018. Regulation of dndB gene expression in Streptomyces lividans. Front. Microbiol. 9: 2387.

19. Sallama LAR, El-Refaia AF, Osmanb ME, Hamdya AA, Ahmeda EM, Mohameda MA. 2010. Some physiological factors affecting rapamycin production by Streptomyces hygroscopicus ATCC 29253. Am. J. Sci. 6: 188-194.

20. More AS, Gadalkar S, Rathod VK. 2017. Extraction of rapamycin (sirolimus) from Streptomyces rapamycinicus using ultrasound.
Prep. Biochem. Biotechnol. 47: 627-632.

21. Dutta S, Basak B, Bhunia B, Chakraborty S, Dey A. 2014. Kinetics of rapamycin production by Streptomyces hygroscopicus MTCC 4003. 3 Biotech. 4: 523-531.

22. Ohira H, Torii N, Aida TM, Watanabe M, Smith RL. 2009. Rapid separation of shikimic acid from Chinese star anise (Illicium verum Hook. f.) with hot water extraction. Sep. Purif. Technol. 69: 102-108.

23. Bierman M, Logan R, O'Brien K, Seno ET, Rao RN, Schoner BE. 1992. Plasmid cloning vectors for the conjugal transfer of DNA from Escherichia coli to Streptomyces spp. Gene 116: 43-49. 